\title{
Pesquisa e criatividade na formação do professor de Geografia
}

Emerson Ribeiro*

Resumo: Esse artigo trata da pesquisa e da criatividade como elementos essenciais para a formação de professores em geografia. A necessidade de pensar a educação e novas práticas pedagógicas em geografia atravessa os caminhos da pesquisa, mas ela por si só, não consegue converter em resultados duradouros. É necessário encontrarmos no processo de criação, outros resultados que leve tanto a geografia acadêmica como escolar a sair do chão. Portanto, trabalhar com pesquisa e criatividade pode ser um dos caminhos para que o professor em formação desenvolva novas habilidades.

\section{Research and creativity in the training of the teacher of Geography}

Abstract: This article deals with research and creativity as essential to the training of teachers in geography. The need for new thinking about education and teaching practices in geography through the paths of research, but it alone can not turn into lasting results. You must find the process of creation, other results that take both the academic geography as a school off the ground.Therefore, working with research and creativity can be one of the ways that teachers in training to develop new skills.
* Doutorando do Programa de Pós-graduação em Geografia Humana da Universidade de São Paulo e professor assistente do departamento de Geociências da Universidade Regional do Cariri (URCA)
Palavras-chave:

Geografia; Pesquisa; Criatividade; Formação; Prática Pedagógica.

Key-Words:

Geography; Exploration; Creativity; Training; Practice Teaching. 


\section{Exórdio}

O presente artigo tenta fornecer subsídios para professores de prática de estágio supervisionado na formação de novos professores.

Esse texto se desenvolverá a partir da discussão de uma pesquisa atrelada ao conhecimento e à criatividade, assim, como a realização de uma prática pedagógica como fonte importante e didática para a formação de professores. Para o alicerce desse texto nos perguntamos. É a pesquisa que nos move? Como a vemos? Abarcando a pesquisa na universidade para a formação de professores e a aplicação de sua importância para escola. Seguindo, apresentaremos o sobressalto, como a pesquisa e a criatividade poderão contribuir para a formação do professor e do aluno, tanto na universidade como na escola básica.

$\mathrm{Na}$ penúltima parte do texto apresentaremos o ensino criativo, abordando uma prática pedagógica em uma escola do ensino básico, fomentando assim, a teoria e a prática desenvolvida pela pesquisa e a criatividade do professor e dos alunos.

Finalizando com o remate a importância da pesquisa e da criatividade para a formação de professores e a necessidade de iniciar essa aprendizagem na universidade.

Formar professores, educadores, docentes, tutores, a lista de sinônimos é extensa, mas nos remetemos nesse texto a usar o termo professores de formação clássica, passando pela universidade, realizando as disciplinas do corpo teórico em geografia e as didáticas pedagógicas, mais estágio supervisionado.

A necessidade de encontrarmos um caminho que de sustentação a uma formação adequada a novos professores de geografia, passa sem duvida pela pesquisa como nos tem alertado outros pesquisadores que trabalham com esse tema, e acrescentamos o ensino por criatividade.

No entanto, diante do quadro se apresenta a sociedade moderna, onde o visual e midiático, passageiro, informacional de respostas rápidas, impressas, no papel, na tela ou via 'MSN', para um mundo tecnológico, de teclas ou de toque, que permite uma interação da criança e de adolescentes cada vez mais cedo com essas tecnologias, levam também a perda de concentração quando usado ao exagero como mostra pesquisas na área Graeml, K. S.; Volpi, J. H. e Graeml, A. R. (2004).

Partindo do exposto sobre a sociedade atual, num mundo de desassossego observamos a perda de concentração e o desinteresse das crianças e adolescentes em sala de aula, desde o fundamental até o superior, assim sendo, passando pelo entendimento do cotidiano, verificamos á necessidade da formação de professores em geografia que atue com competência pesquisa e criatividade frente essas demandas sociais e culturais.

È urgente pensarmos em novas práticas- teórico-didático-pedagógicas que confronte esse cotidiano, portanto, apostamos na pesquisa e a criatividade em geografia para a formação de professores.

\section{Para o alicerce $-E$ É a pesquisa que nos move?}

Geografia Ensino \& Pesquisa, v. 17, n. 2 p. 107-116, maio./ago. 2013

Pesquisa e criatividade na formação do professor de geografia

Se nos remetermos a um passado distante, observaremos pelos livros das ciências que muita coisa mudou na relação do Homem com a produção do espaço/tempo.

Inúmeras pesquisas, tanto no campo comportamental, social, cultural, pedagógico e educacional, quanto no campo técnico, de ferramentas, máquinas, químico-físico e biológico e, também, de material genético, entre tantas outras áreas que abrangem a arte, a guerra, a tecnologia, engenharia, comunicações e serviços, foram criadas e pensadas a partir de pesquisas baseadas em ensaios de erros e acertos. Estes situam-se no campo laboratorial, teóricos ou não, de associações e simulações visando o bem coletivo, um sistema ou uma dada sociedade. 
A sobrevivência da espécie humana está atrelada a capacidade que o homem tem de criar, inventar, duvidar e de dominar o espaço para a sua vivência, conhecer o clima, o planeta, o mar, saber interpretar e se comunicar com as diversas vidas presente no planeta, isso o levou a novas descobertas no campo do saber, utilizando-se do intelecto e do seu corpo, criando esse mundo material pela projeção de sua mente.

Poderíamos dizer que o ato de criar segue a premissa da curiosidade, que nos remete aos questionamentos e dúvidas sobre a nossa existência, de onde viemos e para onde vamos nessa imensidão do universo, e na ânsia pela respostas caminhamos em direção a muitas perguntas moldando esse mundo com as nossas projeções mentais.

O processo de sobrevivência do Homem enquanto ser social se dá pelo ato de responder a algo de sua necessidade ou de outros e para outros, sabemos que o homem modela o espaço conforme as suas conveniências, para isso ele é motivado a buscar e a pesquisar para encontrar as respostas.

Para encontrar as respostas foi necessário concentrar ou não em um dado espaço pessoas para pensar, pesquisar, testar para podermos chegar aos resultados. Esses espaços em muitos lugares são chamados de escola, universidades ou centro de pesquisa.

É na escola que a maioria das crianças aprende a pesquisar ou deveriam e, entender em partes porque as coisas funcionam, a sociedade e a interação do meio, produzindo uma relação de reciprocidade e resultados, mesmos que sejam parciais.

Porém, é na escola que encontramos um profissional que tem de atender e fomentar a pesquisa motivando seus alunos ao conhecimento, abstrato ou concreto, de formulações, induções ou experimentação.

Quando se trata de formação dos profissionais da educação, as Diretrizes Curriculares Nacionais do Ministério da Educação (Parecer CNE/CP n ${ }^{\circ}$ 9, de 8 de maio de 2001, p 23) nos cita que um dos problemas a ser enfrentadas nos cursos de licenciatura refere-se à importância que não se da à pesquisa.

Uma das questões que nos leva a pensar sobre o porquê que tantos profissionais que trabalham com formação de professores há muito tempo aposta e escreve sobre a necessidade do professor em formação ser também um pesquisador, para que estabeleça uma relação entre teoria e prática, esta não se efetiva em muitos casos na prática e no cotidiano escolar. Algumas questões são preeminentes.

A universidade não está realizando o seu papel? Ou o profissional depois de formado abandona a pesquisa devido à alta carga horária de trabalho? Não encontra no cotidiano a inspiração necessária, devido à burocracia? Ou torna-se cômodo a reprodução da geografia apenas pelos livros didáticos?

Muitas indagações poderíamos aqui levantar, porém não é o objetivo central do nosso tema verificar os motivos que muitos professores recém formados deixam de pesquisar, de escrever seus próprios textos e de ensinar os seus alunos a pesquisarem, mais vale a reflexão sobre.

Devemos ressaltar aqui que em muitos casos o ensino 'didático-pedagógico' para muitos professores universitários não é relevante, muitos não tem a preocupação com ensino e pesquisa.

Cabe aos cursos de licenciatura, em especial o de geografia, o trabalho de formar o professor, e esse aspecto deve ser bem examinado (PONTUSCHKA, 2008).

É a pesquisa que nos move? Como formar bons profissionais que após deixar a vida acadêmica, este continue a pesquisar e atuar na relação teoria e prática?

Geografia Ensino \& Pesquisa, v. 17, n. 2 p. $107-116$, maio./ago. 2013

Ribeiro, E. 
outro, pela atomização de determinados espaços: o espaço do conteúdo é ainda o das disciplinas especificas, e o da formação pedagógica, em geral, é caracterizado pela instrumentalização metodológica (PONTUSCHKA, 2008, p.102).

A formação pedagógica deve ter a mesma importância que as disciplinas específicas, pois a influência que o professor tem sobre o alunado é de grande importância e pode em muitos casos deixar impressões positivas ou negativas. A preocupação com os conteúdos selecionados, também pode levar os professores recém formados a trabalhar o conhecimento a favor ou contra os interesses do alunado e da sociedade.

Visto dessa forma, o conhecimento como processo de construção tem como premissa a valorização da pesquisa-ação e seu processo de investigação, entre outros métodos o de reconhecimento do mundo.

\begin{abstract}
Na perspectiva ora exposta, é importante a pesquisa na educação de professores. Pesquisa significa compreender o mundo, mediante respostas que construímos sobre esse mesmo mundo. Essas respostas são expressão da interação entre sujeitos e objetos. Pesquisar pressupõe conhecer o outro - o outro sujeito, o outro objeto. $\mathrm{O}$ ato de pesquisar é um ato de conhecimento: portanto, é parte do processo de educação, ou seja, "consiste em aceitar e respeitar o outro desde a aceitação e respeito a si mesmo" (SUERTEGARAY 2006, p.110)
\end{abstract}

Se a pesquisa é necessária para a formação de professores, também devemos pensar que educação se quer? Que geografia se quer para o professor em formação? É a partir do cotidiano, do lugar que podemos construir um conhecimento geográfico que atue na universidade partindo do ensino básico num movimento de coexistência.

É nessa coexistência que a prática pedagógica requer de si reflexão critica constante, criação e recriação do conhecimento, das metodologias do ensino, da didática e estratégia aplicada, o que pressupõe investigação permanente do formador e do formado.

A importância de pensar como são produzidos os conhecimentos por eles ensinados, e como são avaliados, pode ser um caminho para a reflexão pedagógico e epistemológico, à medida que os conteúdos deixam de serem fins em si mesmo e passam a ser meio para desvendar a realidade e interagir no cotidiano, passa-se a ter uma visão articulada e critica do mundo.

Desenvolver a espacialidade e entender os fenômenos experimentados deve ser
estimulado nos alunos desde a tenra idade com objetos ou sujeitos que permeiam
o campo social e a prática-espacial. Permitir ao aluno construir suas impressões
dialogando com suas representações, para construir suas aprendizagens de acordo
com suas experiências, tendo na avaliação um instrumento de aprendizagem
(RIBEIRO, 2011, p. 97).

A pesquisa aqui ressaltada como pedagógica educativa leva o aluno a pensar e a partir do seu mundo interagir e agir sobre sujeitos e objetos posto no espaço, ampliando a sua espacialidade, direcionado pelo professor na escola, na sala de aula.

Para Demo (1992), mais importante do que as aulas e a transmissão de conteúdos, é abrir espaço para que o aluno trabalhe com temas de pesquisa. A avaliação geraria em torno da produção Geografia Ensino \& Pesquisa, v. 17,própria e não consistiria em provas calcadas nos conteúdos desenvolvidos nas aulas.

n. 2 p. $107-116$, maio./ago. 2013

Pesquisa e criatividade na formação do professor de geografia
Porém, algumas perguntas são básicas quando se trabalha com pesquisa:

1- O que fazer? Colocar o tema a situação problema;

2- Por que fazer? Estabelecer os motivos que justifiquem a pesquisa;

3- Para que fazer? O que se pretende alcançar com a pesquisa, objetivos gerais e específicos;

4- Como fazer? Definir procedimentos metodológicos necessários para visualizar as técnicas 
e a processo a ser utilizado;

5- Onde fazer? Especificar o local o campo de atuação, delimitar a área;

6- Com quê fazer? Delinear os instrumentos de pesquisa que vão ser utilizados e como vão ser aplicados;

7- Quando? Definir etapas e cronogramas, o tempo necessário para a pesquisa.

Para ensinar a pesquisar é preciso que tanto o professor formador como o formado, aqui ambos em formação, na universidade e na escola criem situações e condições didáticas que estimulem a curiosidade e a criatividade.

\section{Sobressalto - Pesquisar exige criação, criatividade}

Todo processo de criação, resulta em uma ruptura. Porem, toda ruptura não resulta num processo criativo duradouro, sem que tenha elementos teóricos fortes contidos em sua própria idealização. (RIBEIRO, 2011:62).

Idealização que começa com a grande explosão a da consciência humana, desde a origem dos tempos, a consciência é o que impulsiona a atividade criativa, na linguagem, nos gestos, nas formas, nas projeções, no ato de um ser que cria.

A consciência "representa muito mais que o big bang. Sem consciência, a realidade e a fantasia carecem de significado; é como se não existissem, pois, o que era para nós o big bang antes de os cientistas o descobrirem"? (LA TORRE, 2005:19).

O que seria do homem primitivo se a grande explosão da consciência não se manifestasse? Viveríamos ainda nas cavernas.

O potencial gerador do desenvolvimento técnico e humano alimentado pela criatividade humana nos tornou o que somos atualmente, o instinto gerador da sobrevivência alimentado pela criação humana na busca pela defesa espacial do corpo e mais tarde da propriedade, sem entrar nos méritos da linguagem, fez com que o Homem inovasse as ideias, estabelecendo normas de convivência, regras, sistemas econômico, educacionais e culturais, portanto, creditamos à explosão da consciência e seu desenvolvimento a investigação, a solução de problemas, a pesquisar a vida e sua continuidade num dado espaço que por nós passou a ser produzido.

\begin{abstract}
A pluralidade de ideias, as várias faces, o agir para o encontrar, faz do homem um perguntador, o ato de criar passa pela história remota do homem. Quer seja transformando a natureza e se transformando, inventando novas técnicas, construindo as relações de produção no espaço, criando uma dinamicidade, relacionada ao desenvolvimento pessoal, social, cultural e cientifica de uma sociedade (RIBEIRO, 2011, p.4).
\end{abstract}

Mas como isso surge, como se dá o processo de criação?

Henry Poincaré estabeleceu os quatro passos básicos para a solução criativa de problemas, que até os dias atuais têm sido citados pelos autores da área (GOLEMAN; KAUFMAN E RAY, 1992). Esses passos não são lineares, mas sim, dinâmicos, interativos e singulares em cada individuo.

Esses passos estabelecidos por Poincaré se resumem a "preparação, incubação, iluminação e aplicação"1. Em Ribeiro (2011), podemos analisar que a criatividade o ato criativo, segundo alguns autores, estão presentes na vida do homem, são atividades ligadas ao cotidiano, ao fazer do homem, ao pensar e intuir para dada ou não solução que se espera, são muitas as relações, movimentos, pluralidades e complexidades que vão sendo descobertas devido a inúmeras técnicas descobertas pelo homem. Essa pluralidade, esse sobressalto aparece e se manifesta, na tenra idade em diversas situações sociais e culturais.

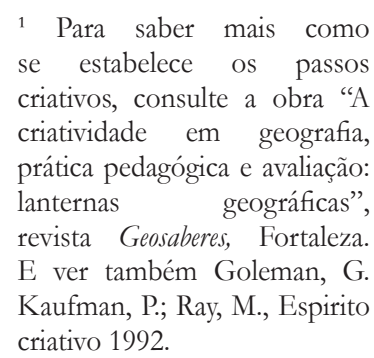
prática pedagógica e avaliação: lanternas geográficas", revista Geosaberes, Fortaleza. E ver também Goleman, G. Kaufman, P.; Ray, M., Espirito criativo 1992.

Geografia Ensino \& Pesquisa, v. 17, n. 2 p. 107-116, maio./ago. 2013

Ribeiro, E. 
A escola em si, tem um significativo papel na criação de oportunidades, vários autores do campo da psicologia e psicanálise, têm apontado a infância como período crucial para o desenvolvimento humano, entre eles, Freud, Piaget, Vygotsky. É na infância que os alunos se assombram com o mundo com o novo, e essa capacidade inventiva e imaginativa tem um forte apelo na esfera da criatividade, é quando a sua mente está em expansão, livre ainda, de préconceitos e de ideologias. É nesse momento da infância e da adolescência que os alunos mediados por seus professores e colegas e pelo meio, possam descobrir seus caminhos. Porém, o que temos muitas vezes, são atividades repetitivas, classes homogeneizadas, respostas repetitivas e copiadas e restrição ao novo, a inovações a pensamentos criativos. (RIBEIRO, 2011, p.7).

Por quê? A profissão de docente requer em muito a participação da imaginação, da criação, para que o estimulo aos alunos parta do professor e cheguem aos alunos, esses códigos, essa linguagem do novo deve permear o campo restrito e espacial dos alunos como se fossem códigos a serem decifrados. Em outras palavras, tem que recorrer ao visual, ao tato, à experimentação, ao corpo, a exemplos, materiais e recursos, etc., que encontre e facilite a aprendizagem.

Estimular a aprendizagem é investigar novas formas de propor algo novo, um conteúdo que leve o aluno a pesquisa e a investigação, a forma como o docente trata a questão a serem ensinadas requer dialogo entre a pesquisa e a criação, criando situações inusitadas, surpreendentes, incríveis, que levem a motivação e inspiração, projeto de sua imaginação criativa.

Quando um professor não dispõe do material adequado, ele pode adotar uma tripla postura: conformar-se com o que tem, buscar outro ou criá-lo. Pois bem, um exemplo bem real são os professores de artes que com materiais descartáveis são capazes de realizar trabalhos surpreendentes. E como fazem? Se perguntarmos, obteremos respostas como estas: imaginação, experiência, combinação de ideias e materiais. A experiência é uma fonte inesgotável de criatividade. (LA TORRE, 2005, p.161).

É essa experiência que o formador e formado e em processo de formação, que ambos temos na relação entre docente e o discente, sendo a interação o fator determinante do rendimento, do estimulo criativo. Um ensino pautado na investigação, pesquisa e criativo, gira em torno da interação entre formador e formado, entre docente e o discente. Em que o clima de confiança, de seguridade, e de compreensão se estabeleça de forma mutua e respeitosa.

Quando isso não ocorre, a frieza, a desconfiança, o conflito entre professor e aluno, tanto a pesquisa como qualquer possibilidade de criação e criatividade que estimule o ensino, assim como a aprendizagem, passa a nos afastar do ensino criativo, motivador que leva a investigação e a criação.

Portanto, a relação entre professor e aluno deve ser positiva, para que ambos alcancem o objetivo, o ensino aprendizagem.

Geografia Ensino \& Pesquisa, v. 17, n. 2 p. $107-116$, maio./ago. 2013

Pesquisa e criatividade na formação do professor de geografia

112 I ISSN 2236-4994
O professor deve ser formado para lidar com o novo e o inesperado. É importante permitir que o aluno discuta, avalie, reflita sobre conceitos, atividades, expressando suas opiniões sobre a realidade na qual está inserido (HAETINGER, 1998). É preciso oferecer condições para que o aluno se relacione, crie, invente e sinta prazer em aprender. Afinal, como vimos nas definições anteriores, criar é um ato intencional, voluntário e carregado de desejo, mas, para ser mobilizado, demanda oportunidades e incentivos (NUNES e SILVEIRA, 2009, p.144).

O novo e inesperado tem as mãos da criatividade, do ato criativo, e em muitas vezes o cotidiano é o que nos fornece a inspiração, a visão. O olhar para baixo, as pequenas coisas já criadas, em movimento ou em estática, pode ser uma fonte de imaginação. O cotidiano estabelece as regras, as condutas, dita ao professor e ao aluno o caminho a perseguir no 
processo de ensino aprendizagem.

\section{Ensino criativo- instalações geográficas}

Diante do exposto, relaciono umas das práticas criativas desenvolvidas no ensino básico, pelos alunos da escola E.E Brigadeiro Tobias no município de Sorocaba. Essa atividade abordou 'As formações florestais no mundo' em que os alunos do $1^{\circ}$ ano do ensino médio passaram do conteúdo teórico para uma prática sugerida pelo professor, manifestando-se a um ato criativo em uma instalação geográfica.

Para encontrar essa prática, essa didática, temos que usar da representação da paisagem, deslocando-a do livro didático para outra forma de expressão da linguagem, essa é as instalações ${ }^{2}$. Exemplificando a didática temos:

1- Abordagem por estimulação sobre o que conhecem sobre o assunto retratado, no caso as formações florestais no mundo, os estratos, relevo e clima, etc.

2- Conteúdos teóricos e delimitação do processo histórico e uso de mapas físicos.

3- Ensaios e erros, apresentação de imagens e mapas.

4- Estabelecer relações entre fatos e conceitos

5- Questionamentos a respeito do tema, competências e habilidades apuradas

6- Avaliação, instalações.

Nesse exemplo os objetos a serem utilizados para representar o conteúdo proposto são:

- Saco de estopa ou ráfia.

- Plantas, isopores, etc.

- Barbante, cola e outros materiais.

- E o fundamental, a criatividade.

Nessa construção os alunos vão se deparar com um problema, como representar o que foi estudado, em um saco de estopa? Essa prática poderá ser realizada em grupos de quatro pessoas, que irá envolver atitudes, compromisso, formas de lidar com o processo avaliativo, criação e discussão envolvendo o grupo, a família passa a ser consultada e em alguns casos se envolvem no conteúdo abordado, liderança é apontada no grupo, distribuição das tarefas e materiais a serem arranjados, etc. Ribeiro (2009).

Figura 1-Instalações em sacos de estopa.

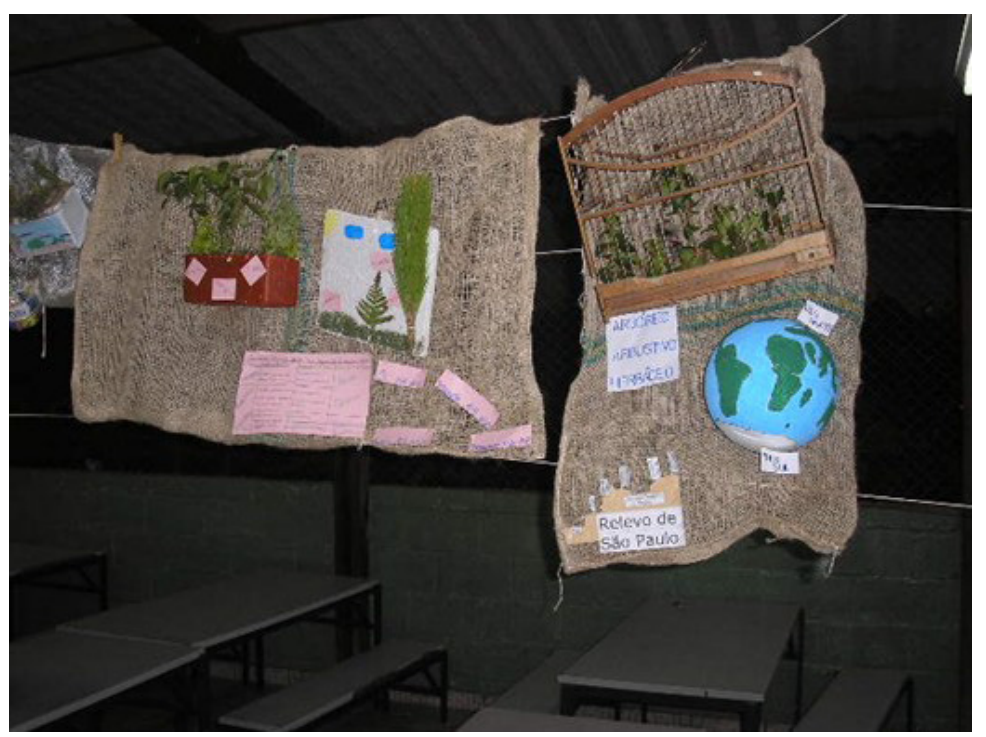

${ }^{2}$ Ver mais em Ribeiro, E.
"Práticas pedagógicas- o
ensino geográfico por
instalações". IX Seminário de
Pós-Graduação em Geografia
da UNESP Rio Claro, 3 a 5
de novembro de 2009. Acesso
http://sites.google.com/site/
seminarioposgeo/anais.

${ }^{3} \mathrm{O}$ termo instalações tem o sentido de dar forma a algo ou materializar o conteúdo estudado, pesquisado, conhecido, com o objetivo de apresentar e expressar algo, sentimento, sua visão de mundo, crítica aos paradigmas, é uma forma de expressão artística, que atende no nosso caso, um conteúdo geográfico. A instalação é montada pelos alunos e professor, para exposição e após a apresentação é desmontada.

Geografia Ensino \& Pesquisa, v. 17, n.2 p. 107-116, maio./ago. 2013

Ribeiro, E. 
Essa prática é exposta na forma de instalações ${ }^{3}$ e, a relação do público (outros alunos da escola, funcionários, etc.) participa dessa interação, desse movimento, num ato de aprendizado.

Acrescento que ao iniciar o ano letivo de 2009 foi realizado um diagnóstico sobre o que eles tinham apreendido e fixado em geografia no ano de 2008 e o resultado foi que $96 \%$ dos alunos lembraram o conteúdo relacionado a essa prática pedagógica, ou seja, conteúdos que são abordados com criatividade são melhores fixados e apreendidos pelos alunos.

Figura-2 Modelos Arbóreos

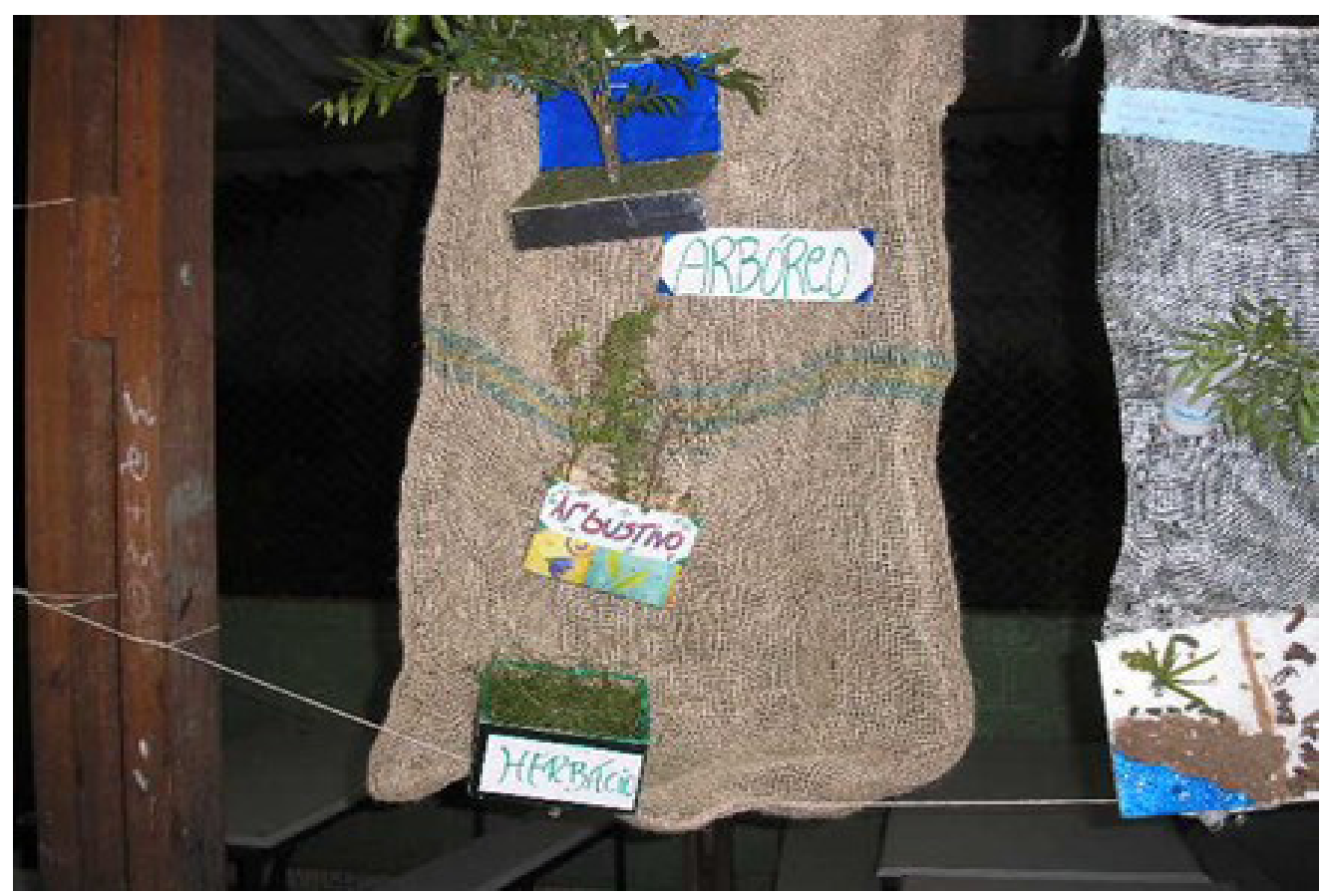

Figura-3 Representação dos estratos arbóreos.

Geografia Ensino \& Pesquisa, v. 17, n.2 p. 107-116, maio./ago. 2013

Pesquisa e criatividade na formação do professor de geografia

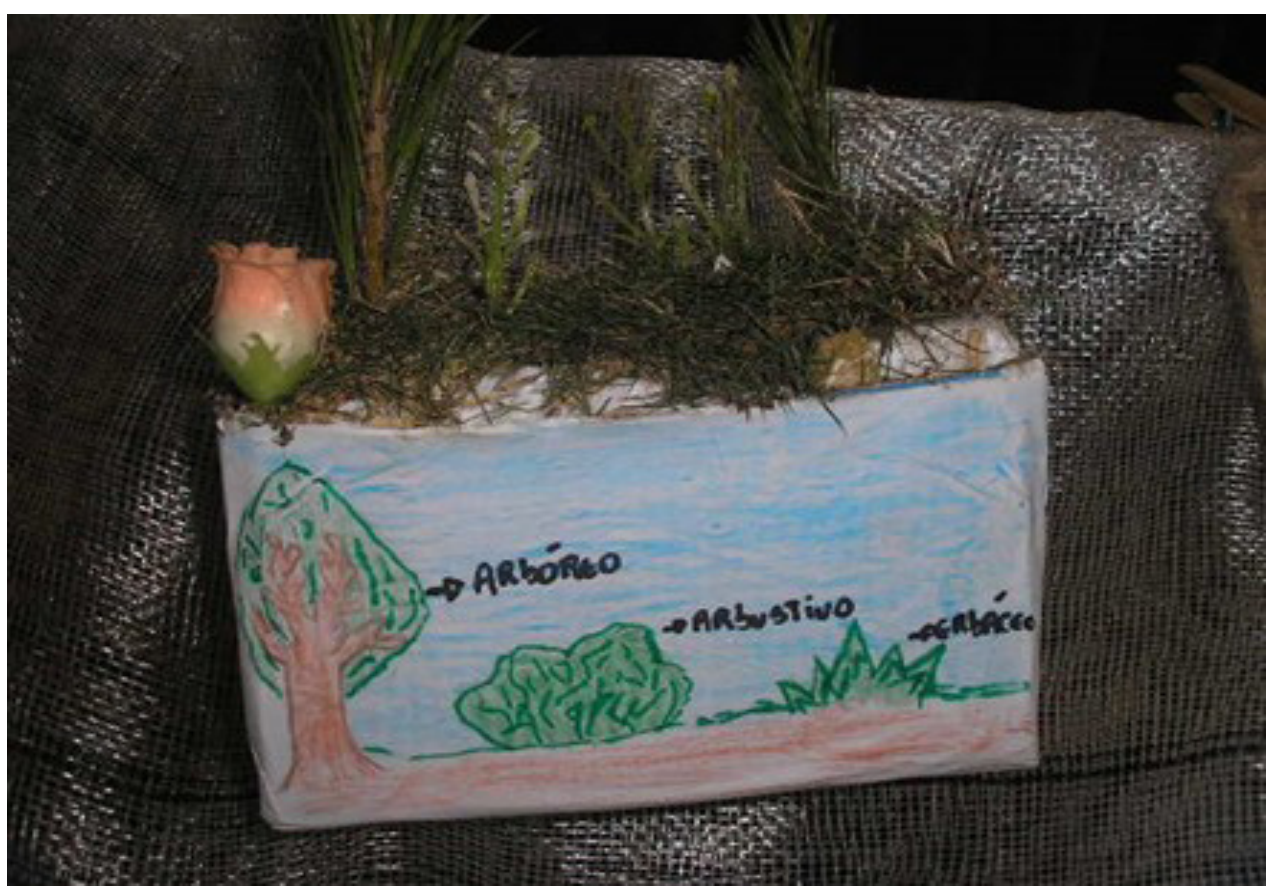


Figura. 4 - Referência da altitude com os estratos.

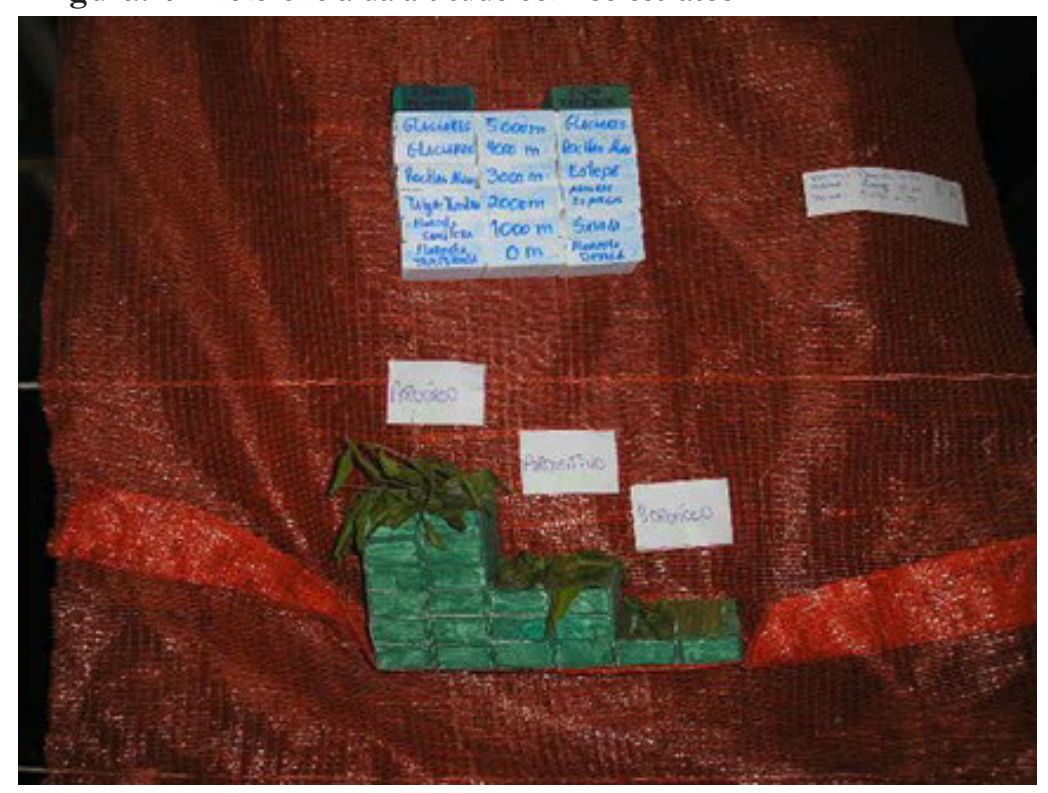

\title{
Remate
}

A pesquisa e a criatividade têm um papel na formação do formado e ambos em processo de formação para a solução de problemas, de equacionar o que está a mais ou a menos, podemos dizer que é o catalisador ou um canalizador.

Formar professores para a pesquisa sem a criatividade, sem aguçar de alguma forma a criação, o seu instinto criativo é continuarmos sem alterarmos o processo de ensino aprendizagem, é ver uma geografia morna chegar aos bancos escolares, é vermos a geografia tradicional, descritiva, continuar a triunfar, serena e calma diante de um mundo agitado.

\begin{abstract}
Para um mundo que se apresenta em constante mudança, complexo e plural o cotidiano é uma leitura do possível, é nele que os grandes artistas tiraram as suas inspirações, Newton, Einstein, Goethe e, é neste mundo que a Geografia enquanto disciplina faz as suas leituras do espaço e da sociedade nas relações de produção. Portanto, é compreendendo a ciência geográfica, mas também, tendo na sua formação a aspiração para o novo, para a criação, que o professor de geografia formará seus alunos para o inesperado, levando-o ao exercício da descoberta (RIBEIRO, 2011, p.7).
\end{abstract}

Exercitar a criatividade é inventar e a invenção é o objetivo do ensino. Pensar sobre algo é dar sobressaltos, é uma ação da inteligência, é preciso duvidar, a duvida nos leva a um caminho, a uma direção, a um conteúdo a um objetivo a um ato a ser criado, inventado pesquisado.

Para tanto, é preciso expor- se ao mundo, caminhar entre os sujeitos e objetos, entre as cidades, campos, escolas, é expor-se ao cotidiano e a uma cotianeidade, retirando a inspiração e a imaginação para o novo, para um ensino aprendizagem que saia do chão.

Formar o docente requer também do formador processo didático criativo, que estimule o docente em formação a criatividade e que para esse, também, estimule o discente ao ato criativo, como aponta La Torre (2005); problematizar, climatizar, estimular, estimar e orientar, tanto para o erro como para os acertos.

Erros e falhas no processo de ensinar e aprender ocorre diante do processo de desenvolvimento do aluno, é nesse momento que o professor deve introduzir dúvidas sobre

Geografia Ensino \& Pesquisa, v. 17, n.2 p. 107-116, maio./ago. 2013

Ribeiro, E. 
tais resultados. Não lhe dando as respostas diretas, mas fazer com que o aluno pense sobre tal situação, mas lhe oferecendo alternativas, como a pesquisa e a investigação para que ocorra o ensino criativo.

É na dúvida e duvidando que a interação entre conhecimento e informação e resultados, podem aparecer na pesquisa/investigativa, tendo como condutor o ensino criativo. Ou seja, é diagnosticando o estado da arte na geografia e abarcando o cotidiano visando à pesquisa e a criatividade que este contribuirá para o processo de formação dos professores.

\section{Bibliografia}

DEMO, Pedro. Formação dos formadores básicos. Em Aberto. vol.12, n. 54,1992. P.23-43.

GOLEMAN, Daniel, KAUFMAN, Paul, RAY, Michael - Espírito Criativo, São Paulo: Cultrix - Amana Key, 1992.

GRAEML, K. S.; VOLPI, J. H. e GRAEML, A. R. Volpi, José Henrique e Volpi, Sandra Mara, Orgs. "O impacto do uso (excessivo) da Internet no comportamento social das pessoas". Revista Psicologia Corporal Vol. 5, 2004.

NUNES, Ana Ignez. Belém. Lima, e SILVEIRA, Rosemary do Nascimento. Psicologia da aprendizagem: teorias e contextos. Brasília: Liber Livro, 2009.

RIBEIRO, Emerson. Práticas pedagógicas- o ensino geográfico por instalações. IX Seminário de Pós-Graduação em Geografia da UNESP Rio Claro, 2009. Anais. Rio Claro, 2009. Disponível em: http://sites.google.com/site/seminarioposgeo/anais.

RIBEIRO, E. A CRIATIVIDADE EM GEOGRAFIA, PRÁTICA PEDAGÓGICA E AVALIAÇÃO: LANTERNAS GEOGRÁFICAS. Geosaberes, Fortaleza, v. 2, n. 4, p. 61-75, ago./ dez. 2011.

RIBEIRO, E. Avaliação ou pescaria?- por uma distinta possibilidade da aprendizagem em geografia na construção de instalações geográficas. Rev. Bras. Educ. Geog., Rio de Janeiro, v. 1, n. 2, p. 91-104, jul./dez., 2011.

PONTUSCHKA; N. N.; PAGANELLI, T. I. ; CACETE, N. H. Para ensinar e aprender Geografia. São Paulo: Cortez, 2007.

PONTUSCHKA, Nidia Nacib. A formação inicial do professor de Geografia. In: FAZENDA, Ivani Catarina Arantes et al. A prática de ensino e o estágio supervisionado. Campinas: Papirus, 15 ed. 2008, pp. 101-124.

SUETERGARAY, Dirce Maria. Pesquisa e educação de professores. In: PONTUSCHKA, Nídia; OLIVEIRA, Ariovaldo U. Geografia em Perspectiva. SP: Contexto, 2002, p. 109-114.

TORRE, Saturnino de la - Dialogando com a Criatividade - da identificação à criatividade paradoxal. São Paulo: Madras, 2005.

\section{Correspondência:}

Emerson Ribeiro - Universidade Regional do Cariri (URCA) Rua Cel. Antônio Luis, 1161 - Pimenta -

Geografia Ensino \& Pesquisa, v. 17, n. 2 p. 107-116, maio./ago. 2013

Pesquisa e criatividade na formação do professor de geografia

116

CEP: 63105-00 - Crato (CE)

E-mail: emerprof@hotmail.com

Recebido em 27 de fevereiro de 2012.

Revisado pelo autor em 09 janeiro de 2013.

Aceito para publicação em 15 de fevereiro de 2013. 